\title{
Statistical modelling proposal for the prediction of the influence on mould growth of interior finishings
}

\author{
Alejandro Reyes Riveros ${ }^{\mathrm{a}, *}$, Ariel Bobadilla Moreno ${ }^{\mathrm{a}}$, Martin H. Spitzner ${ }^{\mathrm{b}}$ \\ ${ }^{\mathrm{a}}$ Department of Building Science and CITEC Building Technology Research Centre, University of Bio-Bio, Av. Collao N 1202 , 4081112 Concepción, Chile \\ ${ }^{\mathrm{b}}$ Department of Civil Engineering and Project Management, Hochschule Biberach University of Applied Sciences, Karlstraße 11, 88400 Biberach, Germany \\ *Corresponding author: +56984425458 e-mail: areyesriveros@gmail.com
}

\begin{abstract}
The interior lining of a home envelope can affect mould growth. This work aimed at proposing the application of statistical modelling that allows predicting the formation of mould on standard solutions when the interior finishings vary.

An experimental evaluation based on bio-hygrothermal simulations and a practical experiment was carried out, the results formed the database to be used in the proposal presented.

The development of a statistical modelling of parameters that represent the characteristics of the finishing material, the underlying layer and the insulation position, can be used to predict the growth of mould, on a static calculation tool without resorting to dynamic biohygrothermal simulations for each variation of interior finishing.
\end{abstract}

Keywords: mould growth, bio-hygrothermal simulation, WUFI, building materials

\section{Nomenclature}

Wt: total water content, Wgb: water content layer of gypsum board, GR: mould growth rate, GI: mould growth index, Y: response variable

Sd: explanatory variable corresponding to equivalent air layer thickness, $\beta_{0}$ : intercept, $\beta_{1}$ : variable multiplier, e: standard residual model's error

\section{Introduction}

Microbial growth in buildings is related to their own deterioration and the materials they are made of, in addition to adverse health effects, being the most important ones the increase in the prevalence of respiratory symptoms, allergies and asthma, as well as the disturbance of the immune system [1]. In the case of Chile, housing failure records from the communes of Temuco and Padre Las Casas during 2019, showed that $85 \%$ of houses delivered reported after-sales problems within the first 12 months after being inhabited. $63 \%$ presented problems related to humidity, and $47 \%$ reported the presence of mould on paint and wallpaper [2].

It is required to determine the nature of the mould microorganism and the material on which it grows, both factors under environmental conditions that are fluctuating [3]. As experienced by Almeida and Barreira [4], after thermal resistance, the selected finishing is the most relevant in terms of mould growth on walls; however, other environmental parameters related to surface humidity cannot be ignored [5].

The objective of this work was to propose the application of statistical modelling that allows predicting the formation of mould on standard solutions when the interior finishings vary. An experimental evaluation based on dynamic bio-hygrothermal simulations and a practical experiment in the laboratory was carried out; the results formed the database to be used in the proposal presented, and they are part of a wider research.

\section{Methodology and case study}

\subsection{Case study}

An internally insulated wooden partition wall was considered with a weighted thermal transmittance value of $0.44\left(\mathrm{~W} / \mathrm{m}^{2} \mathrm{~K}\right)$, similar to that used in a type home Atmospheric Decontamination Program (ADP) in cities in southern Chile [6]. This wall was covered by the following 4 different interior finishing materials, two types of paint: a) Common water-based enamel (CWE) and b) "Anti-mould" water-based enamel (WAE) and two types of wallpaper: c) Vinyl wallpaper (VWP) and d) Common wallpaper (CWP).

\subsection{Theoretical experimental evaluation}

Mould formation was calculated based on the dynamic hygrothermal calculation software WUFI Pro, Bio and VTT. In this way, the work focused on surface mould, evaluating the differences between the results of the different interior finishing materials.

\subsection{Practical experimental evaluation}

An experimental evaluation of mould formation was carried out, building a real wall in a climate-controlled testing building. The geographical location considered is the city of Concepción in Chile (36 $\left.{ }^{\circ} 49^{\prime} 27^{\prime \prime S}, 79^{\circ} 00^{\prime} 49^{\prime \prime} \mathrm{W}\right)$. Chilean standard NCh 1079:2008 [7] classifies Concepción within the South Coastal (SC) climate zone and the Köppen-Geiger climate classification categorices the city as Temperate Mediterranean (Csb).

\subsection{Statistical modelling}

The free statistical analysis software R Project for Statistical Computing, version 2.12.2 is used. This software, from a database composed of predicting variables and response variables, allows to generate a prediction model used the "lm" function, in this opportunity

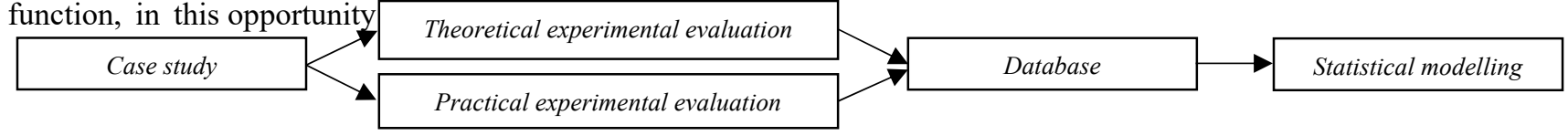




\section{Results}

A linear regression model was adjusted to predict the water content and mould formation based on the predicting variable Sd (equivalent air layer thickness), then each variable is modelled.

Table $\mathrm{N}^{\circ} 1$. Statistics of the models, the variables and parameters of which they are composed.

\begin{tabular}{|c|c|c|c|c|c|c|c|c|}
\hline \multirow[b]{2}{*}{ Model } & \multicolumn{2}{|c|}{ Statistical indicators } & \multirow{2}{*}{$\begin{array}{l}\text { Model's } \\
\text { error } \\
e\end{array}$} & \multirow{2}{*}{$\begin{array}{l}\text { Degree } \\
\text { of } \\
\text { freedom }\end{array}$} & \multirow{2}{*}{$\begin{array}{c}\text { Model } \\
\text { significance } \\
\mathrm{p}^{*}\end{array}$} & \multirow{2}{*}{$\begin{array}{c}\text { Explained } \\
\text { variance } \\
\mathrm{R}^{2}\end{array}$} & \multirow{2}{*}{$\begin{array}{c}\text { Intercept } \\
\beta_{0}\end{array}$} & \multirow{2}{*}{$\begin{array}{c}\text { Variable } \\
\text { multiplier } \\
\beta_{1}\end{array}$} \\
\hline & Variable & $\begin{array}{c}\text { Significance of the } \\
\text { variable in the model } \\
\text { p }\end{array}$ & & & & & & \\
\hline (1) $\operatorname{lm}(\mathrm{Wt} \sim \mathrm{Sd})$ & \multirow{4}{*}{$\mathrm{Sd}$} & 0.33236 & 0.05238 & 2 & 0.3324 & 0.4457 & 1.75747 & -0.03324 \\
\hline (2) $\operatorname{lm}(\mathrm{Wgb} \sim \mathrm{Sd})$ & & 0.19700 & 0.04402 & 2 & 0.1972 & 0.6445 & 5.66120 & -0.04193 \\
\hline (3) $\operatorname{lm}(\mathrm{GR} \sim \mathrm{Sd})$ & & 0.42400 & 58.43000 & 2 & 0.4242 & 0.3315 & -14.45000 & 29.11000 \\
\hline (4) $\operatorname{lm}(\mathrm{GI} \sim \mathrm{Sd})$ & & 0.42600 & 0.19560 & 2 & 0.4264 & 0.3290 & -0.04623 & 0.09690 \\
\hline
\end{tabular}

Model 2 seems to be the most appropriate, as the variable Wgb was significant within the model, with the lowest error, and it also has the highest explained variance of $64,45 \%$. Then, the equation of the chosen model would be as follows:

$$
Y(S d)=\beta_{0}+\left(\beta_{1}\right) * S d \pm e
$$

Thus, using the estimated parameters the predictive equations are determined as follows:

Prediction of water content layer of gypsum board $(\mathrm{Wgb})$ depending on value of equivalent air thickness ( $\mathrm{Sd})$ :

$$
W g b(S d)=5.6612+(-0.04193) * S d \pm 0.04402
$$

Prediction of mould growth rate (GR) depending on the value of equivalent air thickness (Sd):

$$
G R(S d)=-14.45+(29.11) * S d \pm 58.43
$$

In addition to the above, we found correlations for the response variable GR (mould growth rate from WUFI Bio) with the explanatory variable GI (mould growth index GI WUFI VTT) and were subsequently able to fit an additional model. This model has a high explained variance of $90 \%$, a significant explanatory variable within the model and a very low error.

$$
G R(G I)=-0.4294+(299.2448) * G I \pm 1.04
$$

\section{Discussion}

Based on the database of the experimental evaluation, it can be seen that a higher Sd value does not guarantee low mould formation, according to the model it turns out that the higher the Sd value is, the higher the GI and GR values are.

The resulting variables GI and GR are directly proportional, which is consistent with that indicated by Künzel [9] in his comparative study of the results of mould formation index and mould growth rate.

It is proposed to expand the database of this model to cover more types of construction solutions, standardising according to the location of the thermal insulation (variable A) and the type or origin of the interior finishing (according to the Sd value) and its underlying layer (variable B). Furthermore, expanding the database will make the models more accurate.

$$
G R(S d)=S d+A+B
$$

It is proposed to use this predictive equation in a static calculation tool that allows to determine the possible value of mould growth rate (GR), in a simple way and based on limited parameters.

\section{Conclusions}

1. The interior finishing selected for a wall solution will directly influence on the risk of mould growth. Theoretical calculations and the practical experiment showed that the choice of a finishing with a low value of Sd results in low or no risk of mould growth on the interior surface (CWP and WAE).

2. The combination of theoretical calculations with laboratory experiments is necessary, especially when there is no library of climates and materials nationwide yet. In future research, longer experimental evaluation periods of at least 3 years are required to evaluate the sustainability of the different construction solutions and materials that are currently being used in houses.

3. The development of statistical modelling of parameters that represent the characteristics of the finishing material, the underlying layer material and the insulation position, is very useful to determine the mould formation rate on a static calculation tool, without requiring a dynamic bio-hygrothermal simulation for each solution and change of materials.

\section{References}

[1] A. Afshari, E.D.O. Fernandes, M. Hirvonen, K. Séverine, WHO guidelines for indoor air quality: dampness and mould, 2009

[2] ] GFK, Percepción de Satisfacción Clientes Seminario, Temuco, 2019.

[3] A.L. Pasanen, J.P. Kasanen, S. Rautiala, M. Ikäheimo, J. Rantamäki, H. Kääriäinen, P. Kalliokoski, Fungal growth and survival in building materials under fluctuating moisture and temperature conditions, Int. Biodeterior. Biodegrad. 46 (2000) 117-127. https://doi.org/10.1016/S0964-8305(00)00093-7.

[4] R.M.S.F. Almeida, E. Barreira, Monte Carlo Simulation to Evaluate Mould Growth in Walls: The Effect of Insulation, Orientation, and Finishing Coating, Adv. Civ. Eng. 2018 (2018). https://doi.org/10.1155/2018/8532167.

[5] P. Lopez-Arce, H. Altamirano-Medina, J. Berry, D. Rovas, F. Sarce, S. Hodgson, Novel methodology for diagnosis of causes associated with mould growth in dwellings, IOP Conf. Ser. Mater. Sci. Eng. 609 (2019). https://doi.org/10.1088/1757-899X/609/4/042025.

[6] Ministerio de Medio Ambiente, Plan de Descontaminación Atmosférica para las Comunas de Conepción Metropolitano (PDA).pdf, Concepción, 2019.

[7] Instituto Nacional de Normalización, Norma Chilena NCh 1079:2008, (2008).

[8] R Core Team (2020). R: A language and environment for statistical computing. R Foundation for Statistical Computing, Vienna, Austria. URL https://www.Rproject.org/.

[9] C. Bludau, D. Zirkelbach, H.M. Künzel, Berechnung des Instationären Hygrothermischen Vehaltens Mehrschichtiger Bauteile - Feuchtesichere Planung nach EN 15026, J. Chem. Inf. Model. 53 (2013) 1689-1699. 